\title{
GEOTECHNICAL STRUCTURES IN THE ANCIENT WORLD. THE CASE OF THE ZIGGURAT OF UR IN MESOPOTAMIA
}

\author{
ELENA KAPOGIANNI
}

National Technical University of Athens 9 Heroon Polytechniou str. Zografou, 15780 Athens, Greece

email: elkapogianni@mail.ntua.gr

Keywords: Historical Structures, Antiquity, Geotechnical Structures, Earth Retaining Structures, Numerical Modelling, Ziggurat, Cultural Heritage Preservation.

\begin{abstract}
The current study presents several geotechnical structures which were built during the antiquity, aiming to illustrate the ancient technological achievements and to provide an insight into the geotechnical skills in the past. It is evident that ancient civilizations had awareness of the various geological and climatological / meteorological hazards (i.e. natural hazards) that affected the structures and used rather reliable techniques for that time. Furthermore, the study aims to illustrate how some of these are related to modern geotechnical structures. More specifically, the earth retaining techniques used for the construction of the massive pyramid-like structures Ziggurats are shown, highlighting their contribution to structural safety. In this framework, several numerical models have been built and analysed, using the Bishop Analysis for slope stability method and the Finite Element Stress Analysis Method. The results of the numerical simulations are presented and discussed.
\end{abstract}

\section{INTRODUCTION}

Initial efforts of humans to understand the basic principles of geotechnical engineering date back to the prehistoric ages while using soil as a construction material has probably taken place well before the historical records. It is reasonable to assume that the first attempts to add materials to soil to increase its strength were made to stabilize swamps and marshy soils, using tree trunks, shrubs, and other 'reinforcement' materials. Such stabilization efforts may have continued with the development of a more systematic approach where for example tree trunks were uniform in size and length and tied together to form a uniform surface. Such an example are the corduroy roads (Figure 1), which were roads made of tree trunks in around $3000 \mathrm{BC}[1]$.

Furthermore, retaining and fortification walls were often built during the antiquity, usually from stones and mud. Many archaeological sites worldwide include such walls, relatively well preserved. Foundation engineering techniques were also well known, aiming to control the water content in the soil and to distribute the loadings of the constructions uniformly. In the following section, examples of various geotechnical related constructions of the antiquity are shown. 

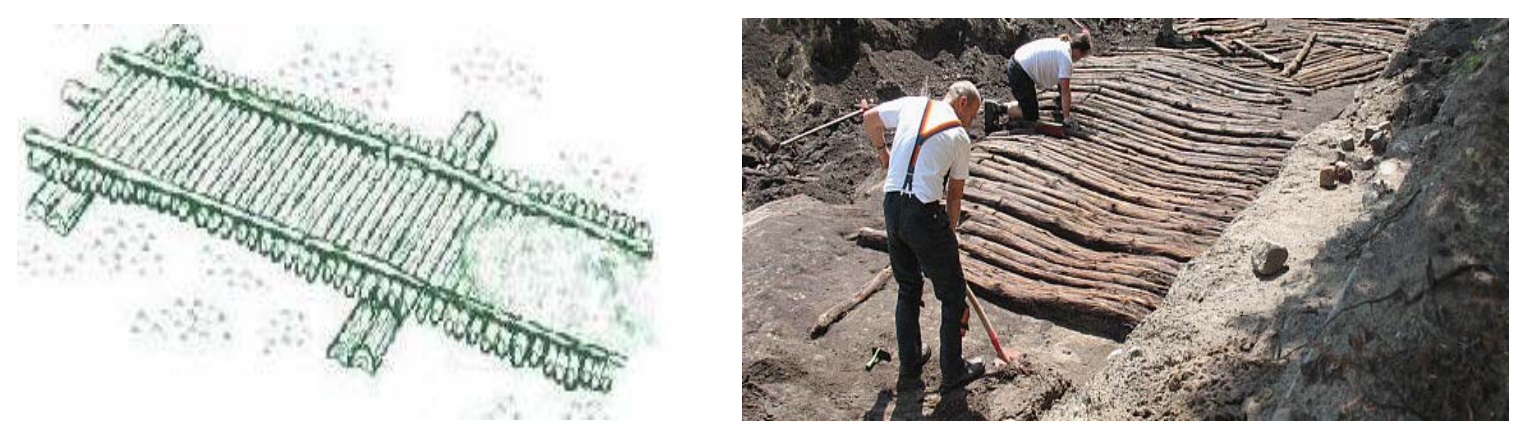

Figure 1. Sketch of a corduroy road. (left) and excavation of a corduroy road (right).

\section{ANCIENT GEOTECHNICAL STRUCTURES}

Regarding ancient geotechnical structures, a well documented example consist the fortification walls of Troy [2], built during the Bronze Age (1700-1300 BC). The great walls of Troy were constructed using large hewn stones attached together, including also a layer of soil between foundation and bedrock (Figure 2). The specific structure is considered to be quite atiseismic, since the earth fill of the subfoundation acted like a seismic absorber. Another important example of ancient geotechnical structure is the polygonal wall in Delphi, Greece, where the well known ancient sancturary of Pythia was located. The walls were built from stones with curved joints that had excellent adaptation between them (Figure 3).
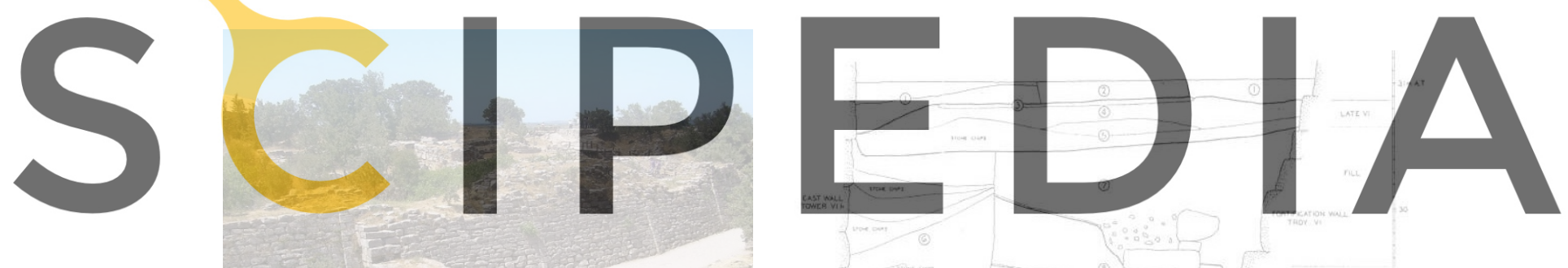

Register for free at https//www.scipedia.com to download the version without the watermark

Figure 2. A view of the Troy wall (left) and a section showing the layer of earth between the foundation and the bedrock (right) (Blegen 1953).
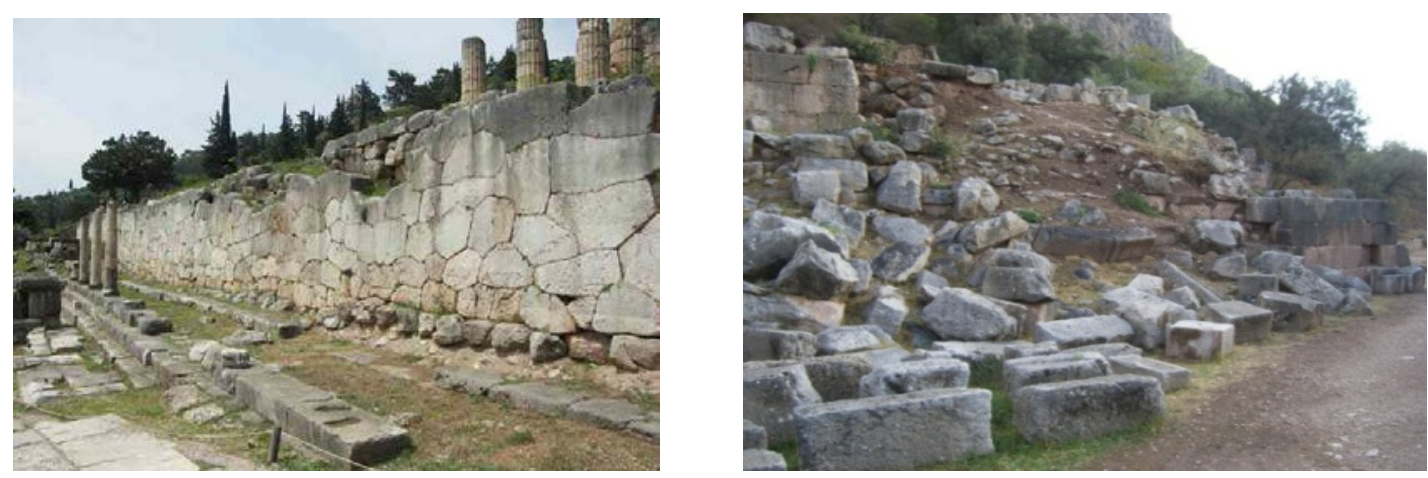

Figure 3. The polygonal walls in Delphi, Greece (left), a wall failure in Delphi, Greece (right). 
The very important archaeological site of the Acropolis of Athens, also includes extensive geotechnical works. More specifically, the Acropolis Hill was chosen due to its geomorphology by the fist inhabitants of Attica since the Neolithic period (4000 / 3500-3000 BC). Among the standing monuments of the Hill (i.e. Parthenon; Erechtheion; Propylaia; Arrephorion etc), the Circuit (Perimeter) Wall serves a pure geotechnical purpose, since it functions as a typical gravity wall, retaining the backfill that forms the plateau of the Acropolis and has total length of about $800 \mathrm{~m}$ and variable height areas 5-20 m [3], [4]. In Figure 4 the Acropolis Hill and the Circuit Wall are shown and a cross section of the south-east side of the Wall.
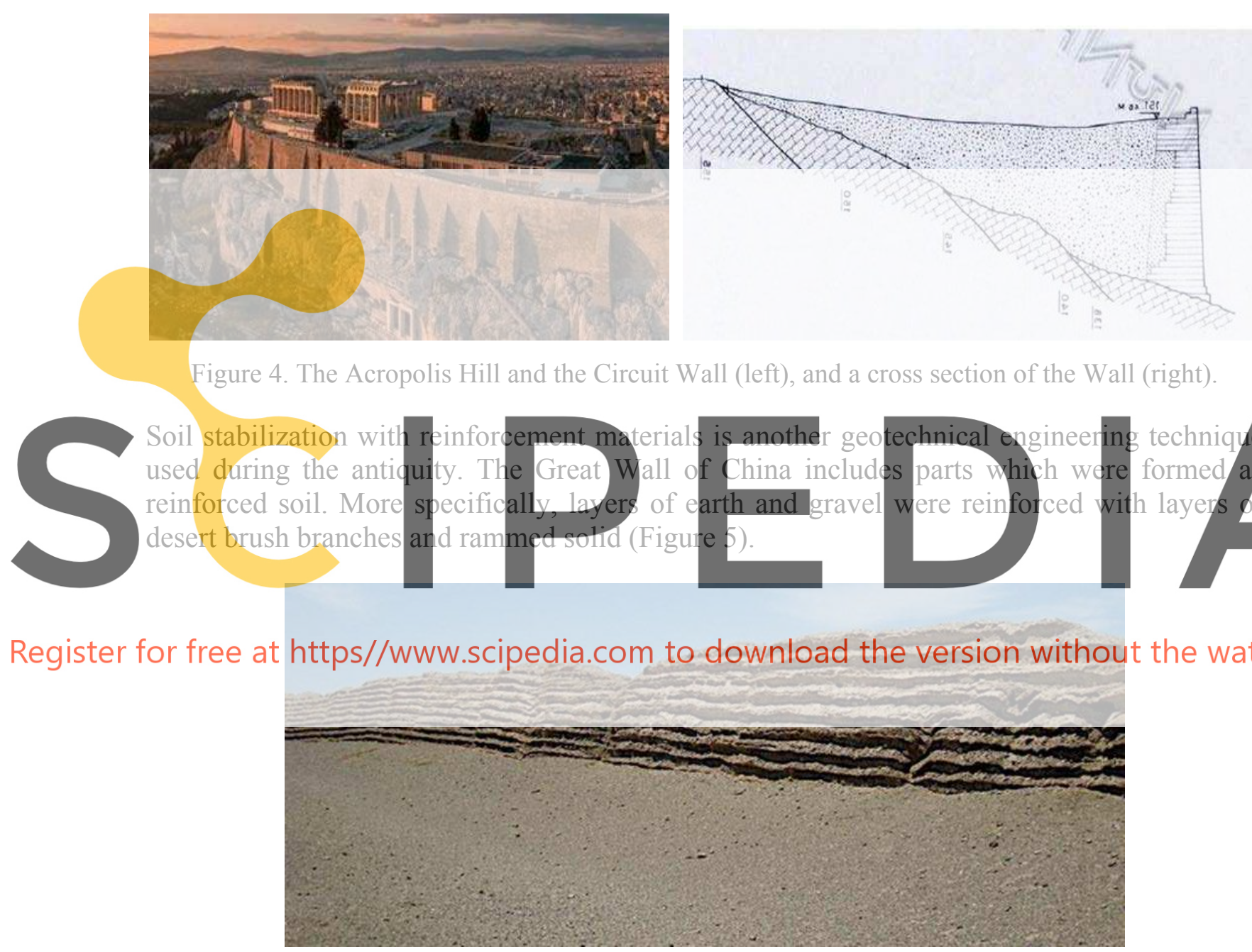

Figure 5. Surviving Great Wall from the Han Dynasty.

Earth reinforced techniques also included the Ziggurats (Figure 6) which were built by the Sumerians, Babylonians, and Assyrians in ancient Mesopotamia, from the $40^{\text {th }}$ to the 6 th century BC. [5]. These constructions consisted of walls covered with clay bricks and layers of mats made of baskets, which were placed in the mud between the bricks as horizontal reinforcements. Additional reinforcement was included in some of the Ziggurats in the form of ropes, about $50 \mathrm{~mm}$ in diameter each, placed perpendicular to the wall at even intervals, in horizontal and vertical directions. 


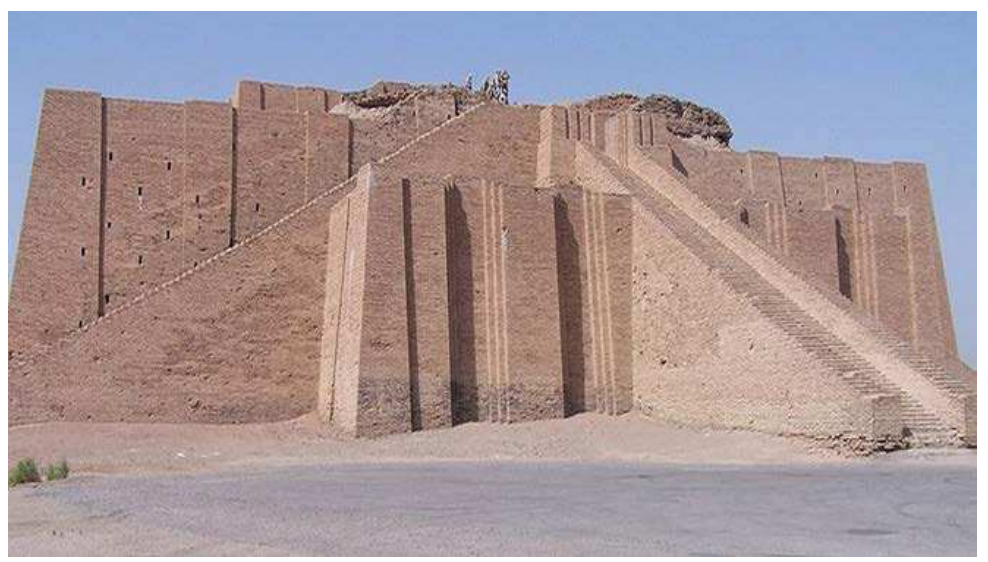

Figure 6. The reconstructed facade of the Great Ziggurat of Ur.

\section{ZIGGURATS AND EARTH REINFORCEMENT}

The operation of reinforced earth lies in the combination of the soil and reinforcement, in such way that a new composite material is created, combining their best characteristis. More secifically, the low cost soil has high resistance to compression and represents the largest volume of the construction material. On the other hand reinforcement materials increase the

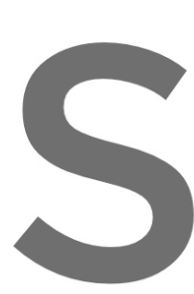
tensile strength and cor

improved mechanical prtiction between si where friction between
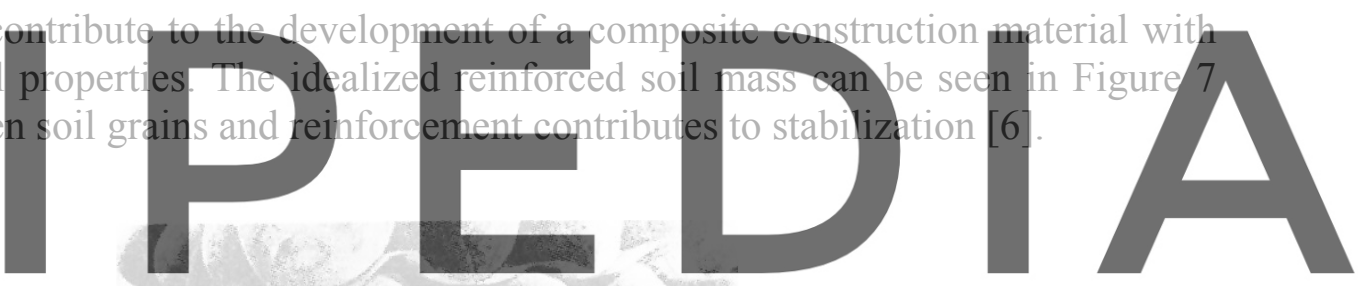

Register for free at https//www.scipedia.com to download the version without the watermark

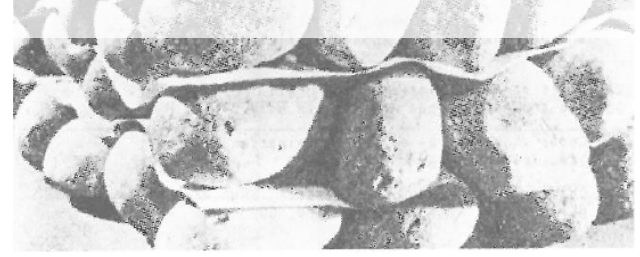

Figure 7. Idealized reinforced soil mass.

One of the oldest applications of soil reinforcement can be found at the Ziggurats in ancient Mesopotamia and western Iran. The Ziggurats were massive pyramid-like structures with the form of terraced steps of successively receding levels. They were constructed of clay bricks varying in the thickness between 13-40 cm, reinforced with woven mats of reed laid horizontally on a layer of sand and gravel at vertical spacings varying between 50 and $200 \mathrm{~cm}$. A characteristic Ziggurat is the Aqar Quf structure, near Baghdad, Iraq which originally is believed to have been over $80 \mathrm{~m}$ high and now is $45 \mathrm{~m}$ tall [7]. Reeds were used to form plaited 
ropes approximately $10 \mathrm{~cm}$ in diameter which passed through the structure and acted as reinforcement (Figure 8).
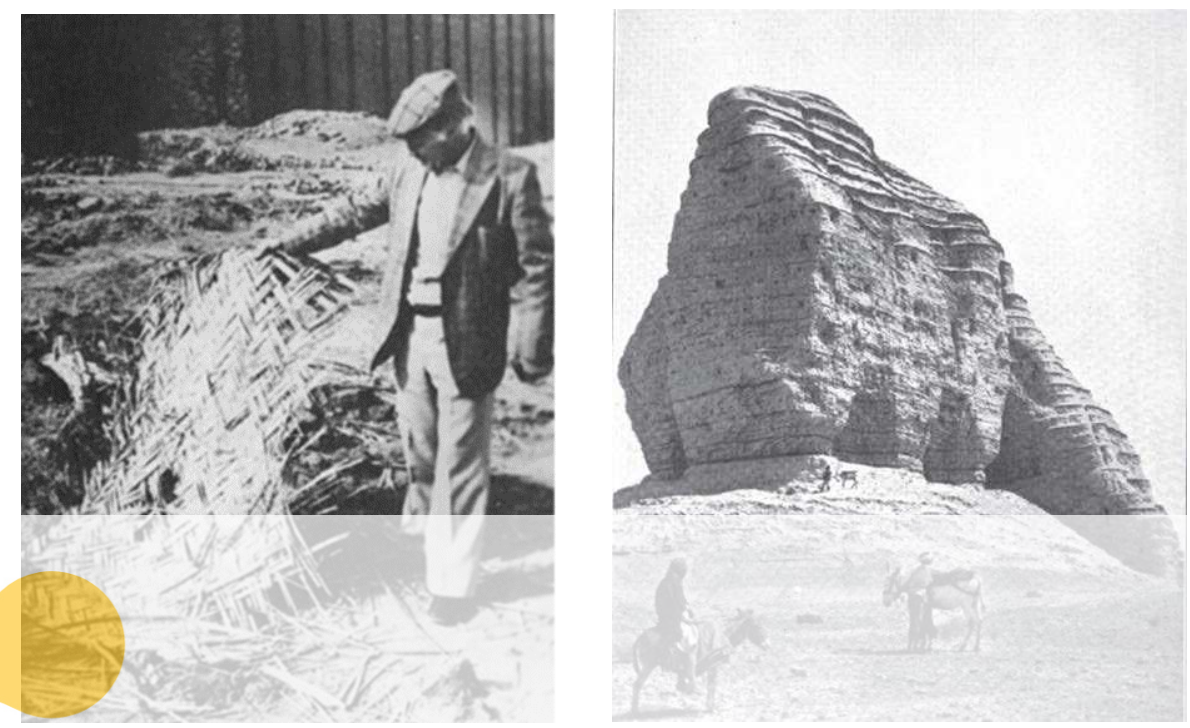

Figure 8. Stabilisation of foundations and brickworks with reet mats at Ziggurat temple at Aqar Quf (left). The Ziggurat of Aqar Quf in 1915 (right).
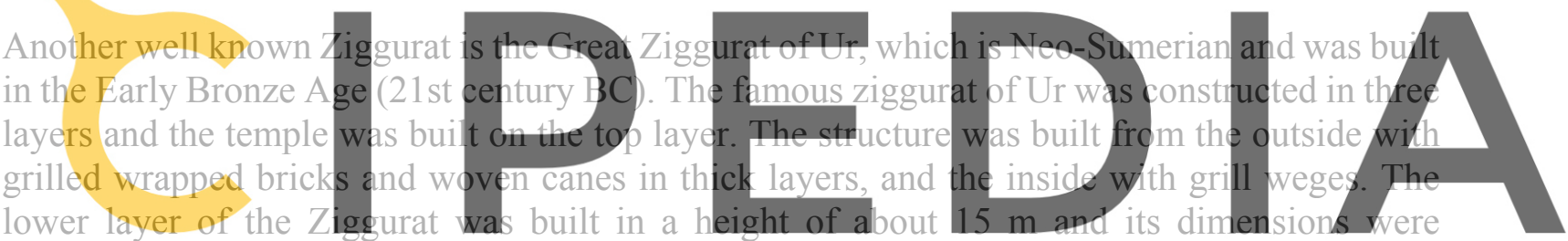

approximately $60 * 45 \mathrm{~m}$. The second layer was built with a height of about $6 \mathrm{~m}$ and dimensions

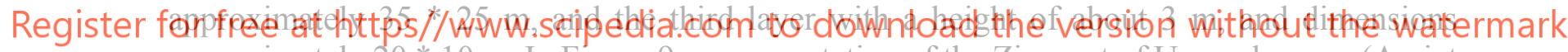
approximately $20 * 10 \mathrm{~m}$. In Figure 9 a representation of the Ziggurat of Ur can be seen (Amiet et al. 1981) and relatively recent restoration works.
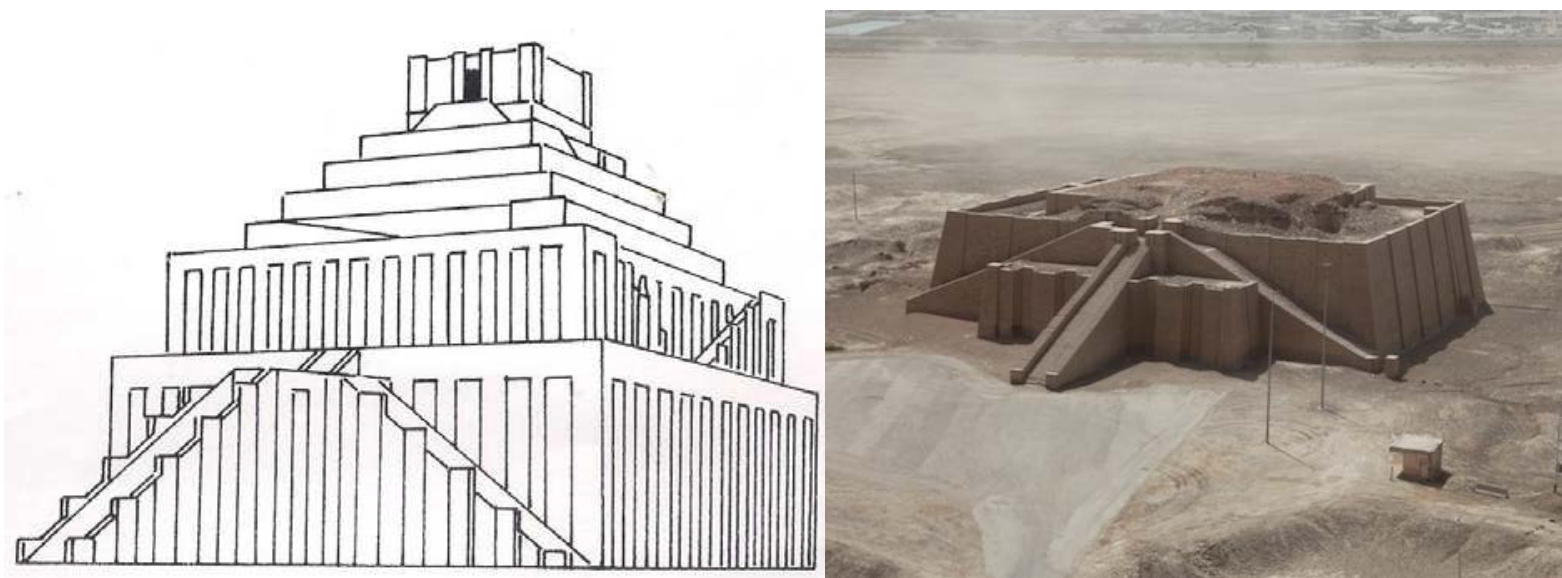

Figure 9. Representation of Ziggurat (left) and extensive reconstruction works (right). 


\section{NUMERICAL MODELLING}

In the current section numerical simulations of constructions similar to the great Ziggurat of Ur are shown, focusing on the soil reinforcement that was included at the initial ancient construction. More specifically two dimensional, three-step numerical models have been built, with a height of $15 \mathrm{~m}$ and length $45 \mathrm{~m}$ for the first step, a height of $5 \mathrm{~m}$ and length $30 \mathrm{~m}$ for the second step, and a height of $3 \mathrm{~m}$ and length $26 \mathrm{~m}$ for the third step. The temple that existed at the top of the highest step has been replaced with a uniform loading, equal to $100 \mathrm{kN} / \mathrm{m}$. Sand was used for the soil material with friction angle equal to 35 degrees. Inclined walls were included at the exterior surface of every step, following their inclinations. Two different numerical methods have been used and more specifically a) numerical modelling with the Bishop Method for slope stability analysis, and b) numerical modeling with the use of the Finite Element Stress Analysis. The results are presented and discussed in the following and the importance of the horizontal reinforcement of the soil material is highlighted.

In Figure 10, the first model built can be seen, as it was analysed with the Bishop Method for slope stability analysis. This model includes inclined walls at the exterior surface of every step, without horizontal reinforcement layers at the soil mass. The Safety Factor (SF) that has been calculated is significant smaller than 1, which would be relatively acceptable SF. More specifically it has been calculated equal to 0.389 and the shape and center of the failure mechanisms are shown. The most critical failure mechanism is located at the fist step of the construction, which is expected since this step is the highest one (15m), with the steeper inclination (80 degrees). shown, and the results side of the numerical ino 12 , the previous model and the results show that while the critical failure mechanisms are fewer, there is no impact to

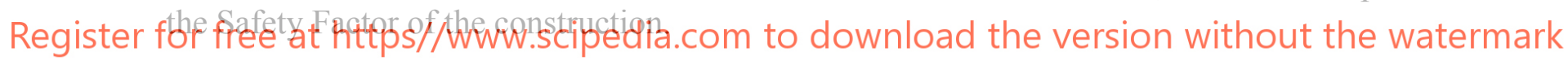

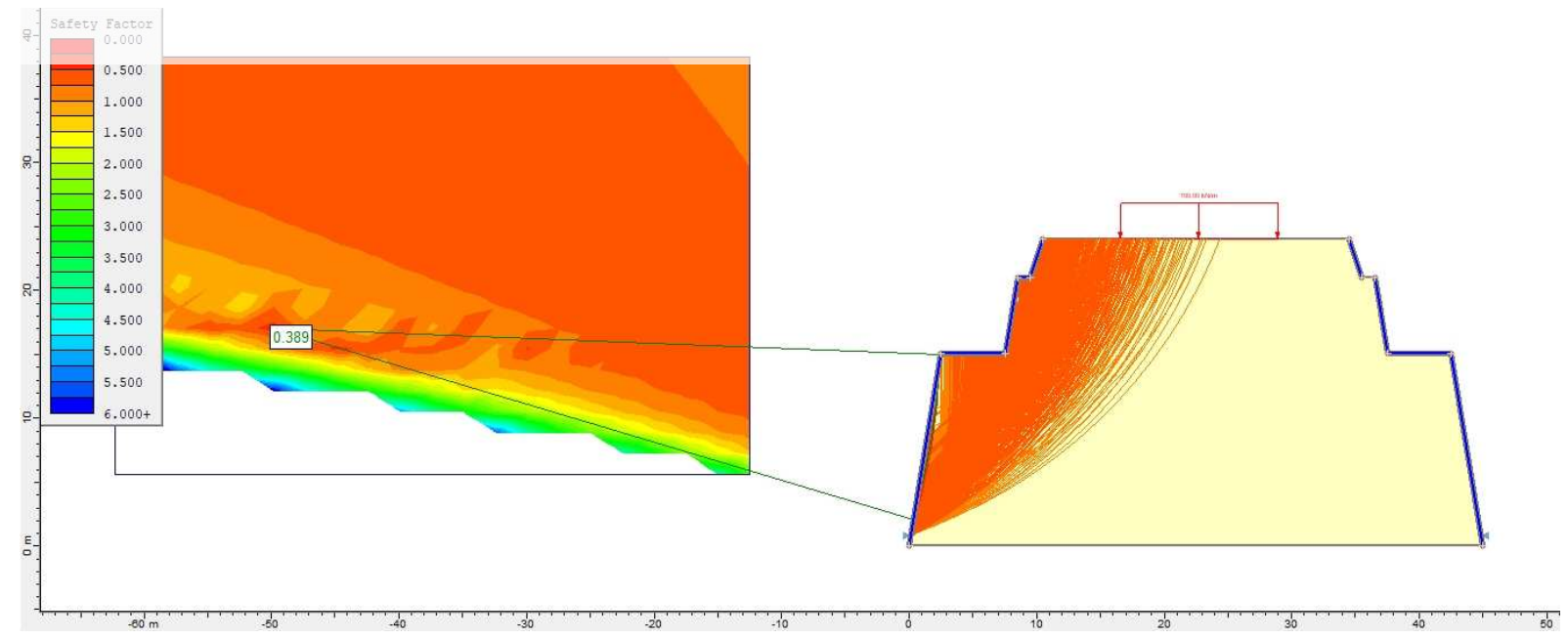

Figure 10. Numerical Model including inclined walls. Safety Factor: 0.389. 


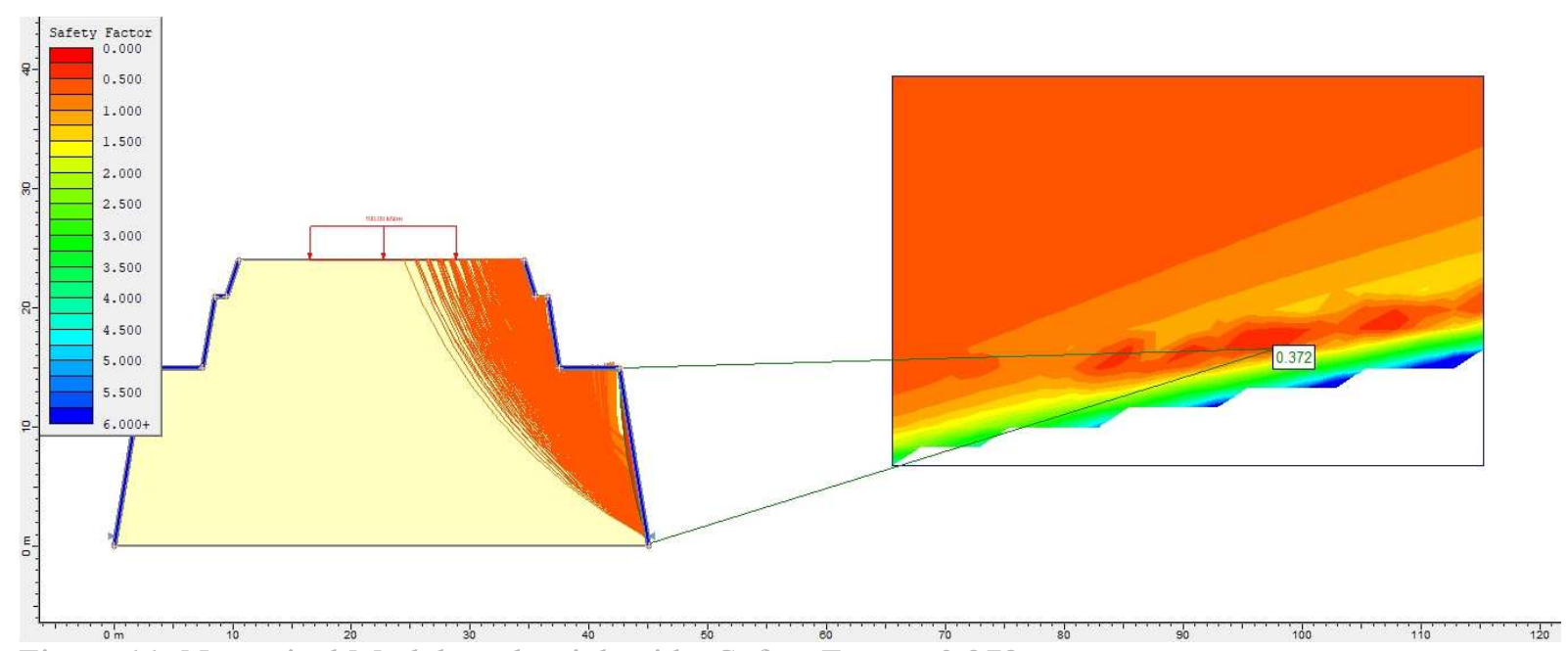

Figure 11. Numerical Model on the right side. Safety Factor: 0.372.
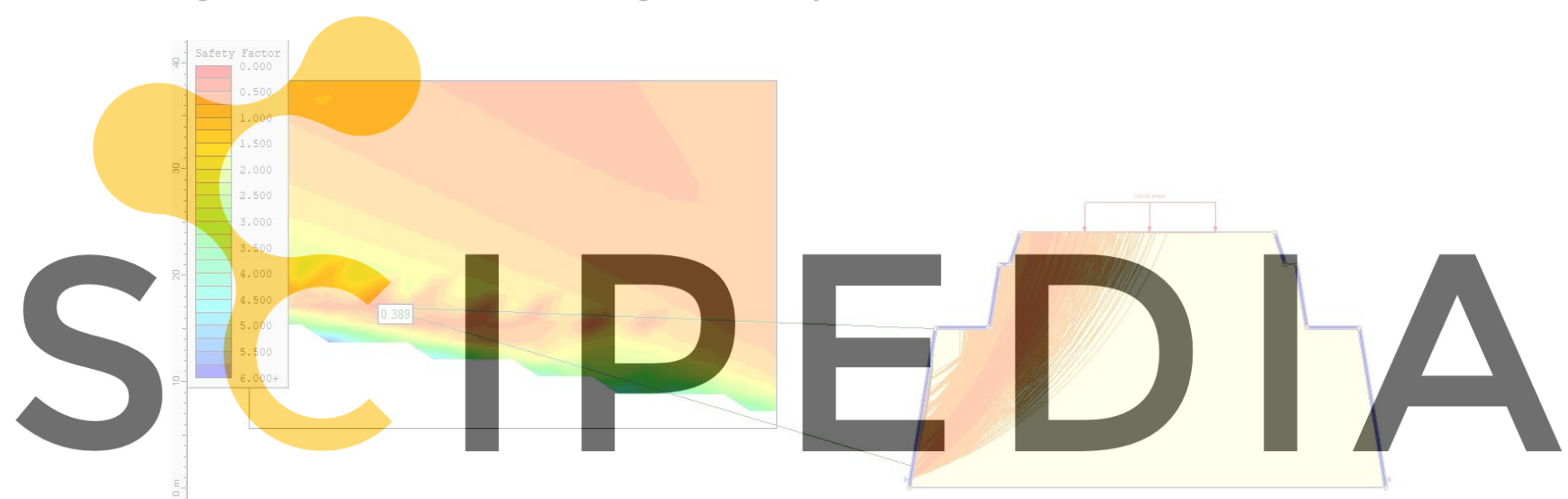

Register for free at https//www.scipedia.com to download the version without the watermark

Figure 12. Numerical Model including inclined walls with increased strength. Factor of Safety: 0.389.

For the next series of analyses, horizontal reinforcement has been included in every step of the construction. More specifically, in Figure 13, horizontal reinforcement with tensile strength equal to $\mathrm{T}=40 \mathrm{kN} / \mathrm{m}$ has been added with a length of $5 \mathrm{~m}$ and spacing (i.e. distance between support) equal to $1 \mathrm{~m}$. The new Safety Factor is 0.780 , significant higher that the Safety Factors that were calculated in Figures 10 to 12. Furthermore, the failure mechanism is now extended from the top to the bottom of the model and not exclusively to the first step. In Figure 14, the length of the reinforcement layers has been increased from $5 \mathrm{~m}$ to $15 \mathrm{~m}$ for the first and second step and to $10 \mathrm{~m}$ for the third step of the construction. The tensile strength of the reinforcement layers remains equal to $\mathrm{T}=40 \mathrm{kN} / \mathrm{m}$. As can be noted, the Safety Factor increases significantly to 1.071 , higher than 1, indicating that the length of the reinforcement layers plays an important, stabilizing role to the construction. 


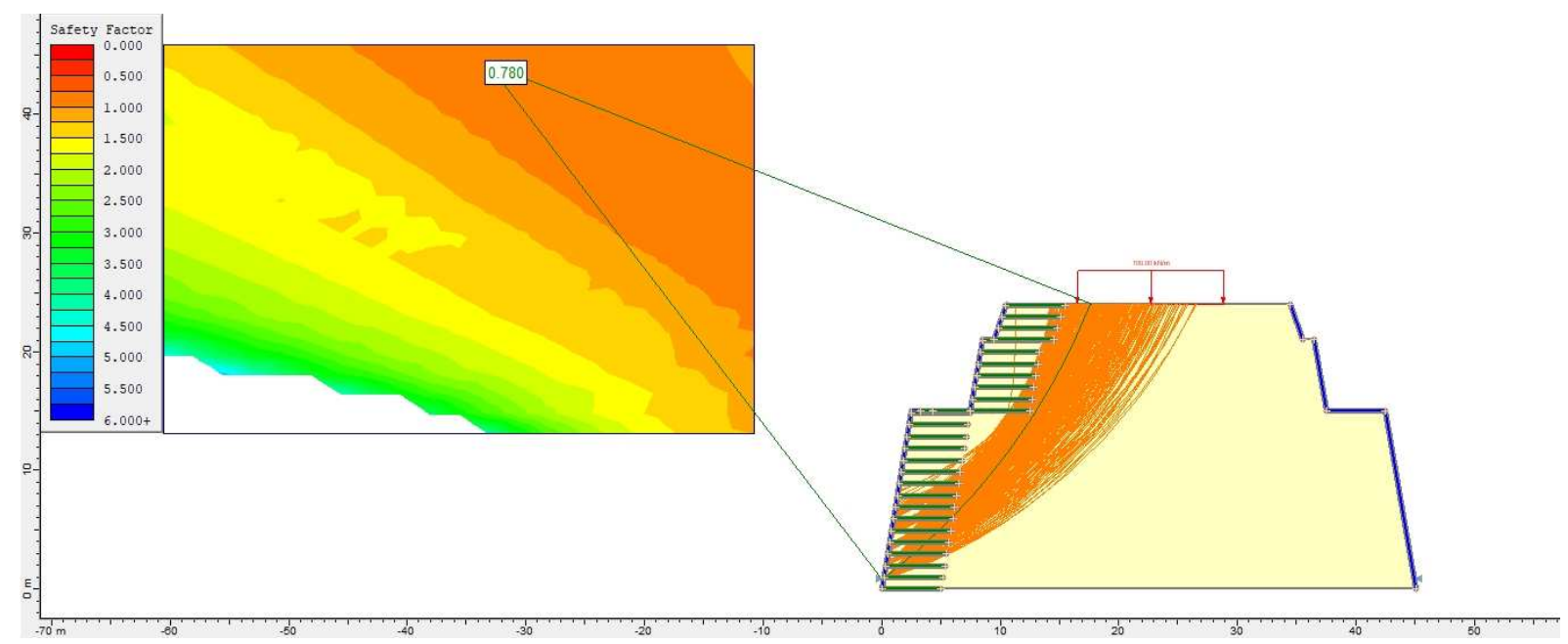

Figure 13. Numerical Model including inclined walls and horizontal reinforcement with tensile strength equal to $\mathrm{T}=40 \mathrm{kN} / \mathrm{m}$ and reinforcement length equal to $5 \mathrm{~m}$. Safety Factor: 0.780
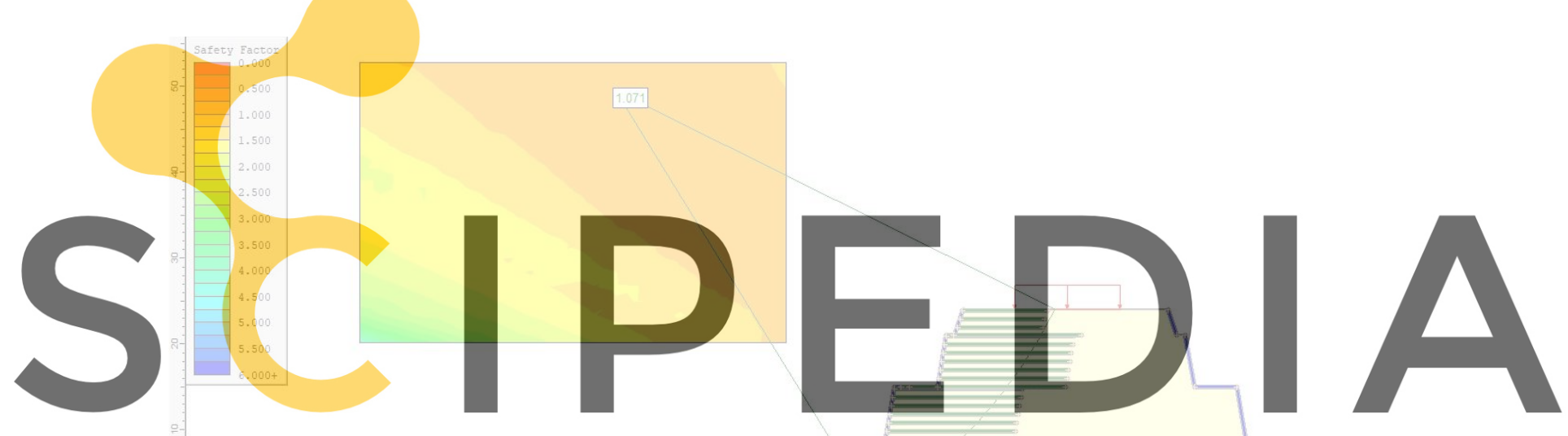

Register for free at https//www.scipedia.com to downloadthe version without the watermark

Figure 14. Numerical Míodei inciuding inciined wails and horizontal reinforcement with tensile strength equal to $\mathrm{T}=40 \mathrm{kN} / \mathrm{m}$ and reinforcement length equal to 15 and $10 \mathrm{~m}$. Safety Factor: 1.071 .

The next series of analyses present results of the same previous models analysed anew with the Finite Element Stress Analysis Method. The first model can be seen in Figure 15 and more specifically a three stepped soil construction with walls at the exterior that follow the inclination of the three steps. Uniform loading of $100 \mathrm{kN} / \mathrm{m}$ has been included on the top of the construction. This model is similar to the model shown in Figure 10 and was analysed with the Bishop Method for slope stability analysis. In Figure 16 the maximum shear strains developed are shown and very high deformations are noted. Additionally, the strain vectors can be seen (in red). Horizontal reinforcement materials have been included at the left side of the model as can be seen in Figure 17. The reinforcement is uniform (i.e. with a spacing of 1m), with a length of $15 \mathrm{~m}$ for the first two steps and $10 \mathrm{~m}$ for the third step of the construction. In Figure 18 the maximum shear strains developed are shown and significant deformations are noted on the right side of the model, where no reinforcement has been included. The variation between the left 
and right side of the model in terms of strains developed is significant, demonstrating the importance of the reinforcement layers on the overall safety of the construction. Furthermore, the failure mechanism on the right side can be seen. Finally, in Figure 19 the strain vectors are shown (in red) demonstrating the significant differences between the left and the right side of the model.

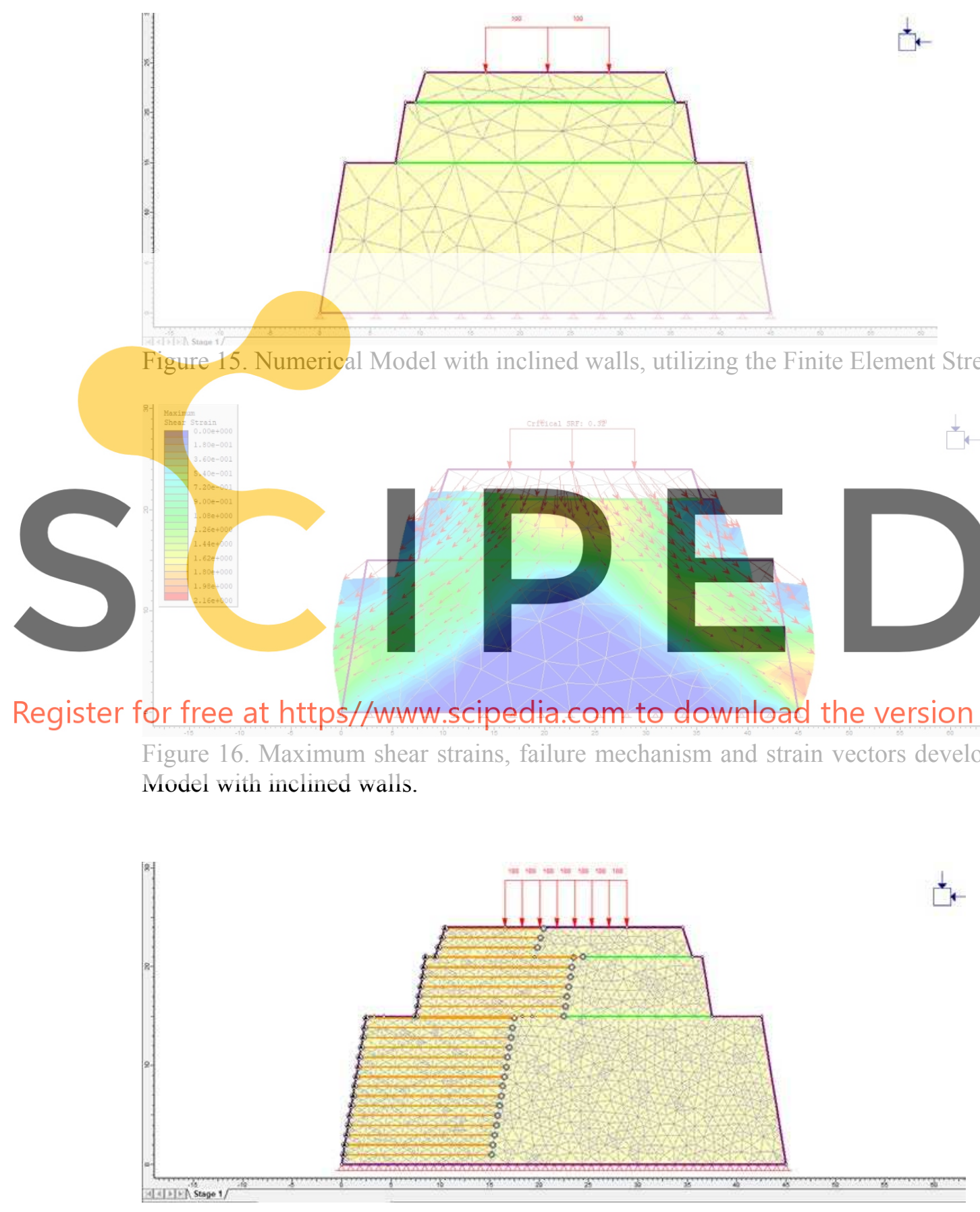

Figure 15. Numerical Model with inclined walls, utilizing the Finite Element Stress Analysis Method.

Figure 17. Numerical Model with inclined walls and horizontal reinforcement at the left side. 


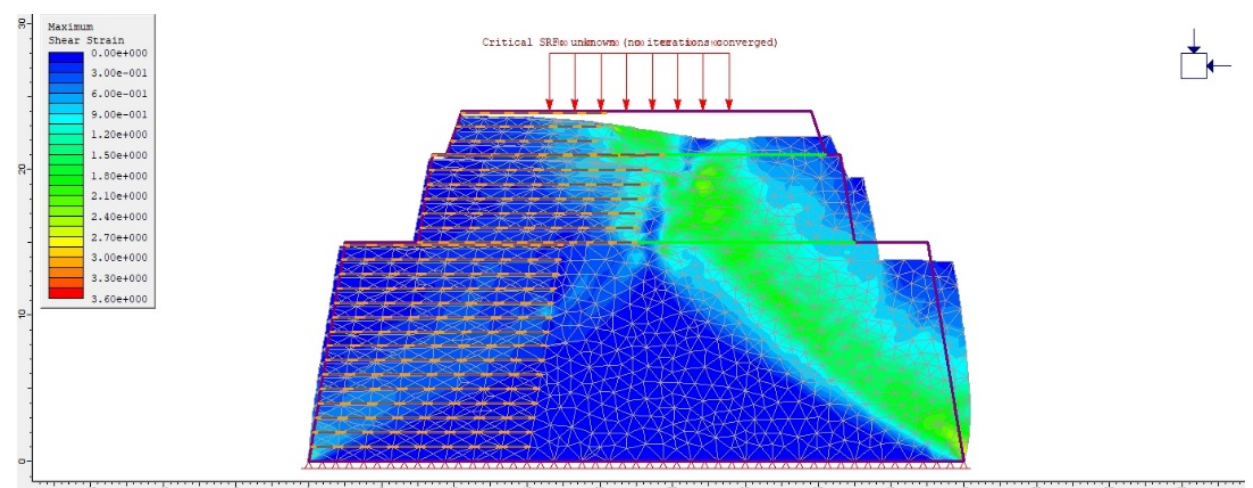

Figure 18. Maximum shear strains developed and failure mechanism at the Numerical Model with inclined walls and horizontal reinforcement at the left side.

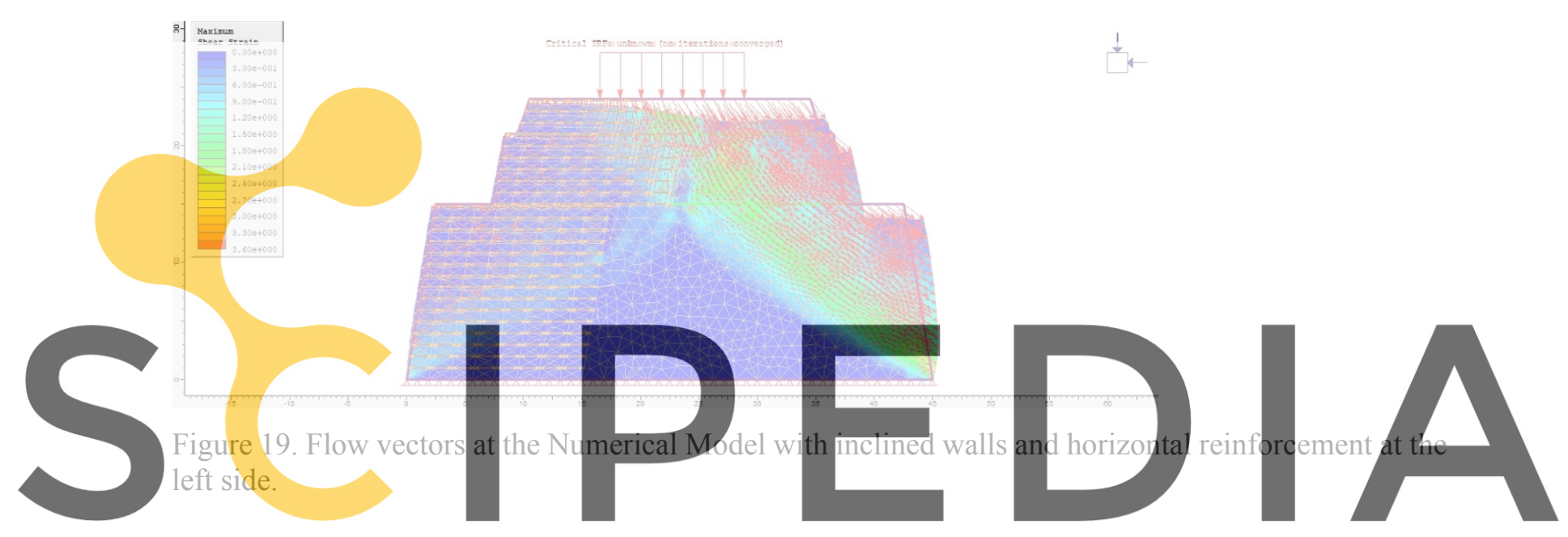

\section{Register for freeGt GetpsXAwww.scipedia.com to download the version without the watermark}

In the current study various geotechnical structures built in the antiquity have been presented, aiming to demonstrate that ancient civilizations had awareness of advanced construction techniques and applied reliable methods to deal with structural loadings and various natural hazards. These structures can be found in various archaeological sites worldwide. Furthermore, the earth retaining techniques used for the construction of the massive pyramid-like structures Ziggurats were examined and more specifically, the contribution of soil reinforcement to structural safety.

Several numerical models were analyzed utilizing the Bishop Analysis for slope stability method and the Finite Element Stress Analysis Method. The results of the numerical simulations were presented and discussed. The analyses showed that soil reinforcement plays an important role to structural safety, increasing significant the Safety Factor of the constructions. Furthermore, the increased length of the reinforcement is also a factor that benefits the high, inclined soil-mass structures. The numerical models utilizing the Finite Element Stress analysis method are in good coherence with Bishop Analysis numerical models and showed that the reinforcement materials decreased the strains and deformations of the 
construction. It is evident that it would be rather difficult to build the Ziggurats at the specific heights and with such steep inclinations, without the reinforcement materials.

\section{ACKNOWLEDGMENTS}

The author is grateful for financial support provided by the State Scholarships Foundation of Greece (IKY). This research is co-financed by Greece and the European Union (European Social Fund- ESF) through the Operational Programme «Human Resources Development, Education and Lifelong Learning» in the context of the project "Reinforcement of Postdoctoral Researchers - 2nd Cycle" (MIS-5033021), implemented by the State Scholarships Foundation (IKY).

\section{REFERENCES}

[1] Dewar, S., 1962. The Oldest Roads in Britain, The Countryman, Vol. 59, No. 3, pp. 547555.

[2] Blegen, C.W., 1953. Troy: Excavations Conducted by the University of Cincinnati, 193238, vol. 3, Princeton.

[3] Kapogianni E., Psarropoulos P.N., Kokoris, D., Kalogeras I., Michalopoulou, D., Eleftheriou, V., Sakellariou M.G. 2020. Impact of Local Site Conditions on the Seismic Response of the Athenian Acropolis Hill. Geotechnical and Geological Engineering, Springer International Publishing. https://doi.org/10.1007/s10706-020-01589-8

[4] Kapogianni, E., Kalogeras, I., Psarropoulos, P., Michalopoulou D., Eleftheriou, V., Sakellariou, M. Suitability of Optical Fibre Sensors and Accelerographs for the Multidisciplinary Monitoring of a Historically Complex Site: The Case of the Acropolis Circuit Wall and Hill. Journal: Geotechnical and Geological Engineering, Springer International Publishing (2019). Volume 37, Number 5, p 4405

[5] Ratchet, G., 1983. Dictionnaire L' Archéologie, Ed. Robert Laffont, S.A., Paris, France.

[6] Vidal, H., La Terre Armée, 1969. Annales de L Institut Technique du Batiment et des Travaux Publics, No. 259-260, pp. 1-59.

[7] Ziegler, M., 2017. Application of Geogrid Reinforced Constructions: History, Recent and Future Developments, Procedia Engineering 172, 42 - 51 